\title{
Assessing the Role of Antibiotic Therapy in Transoral Endoscopic Thyroidectomy Vestibular Approach
}

\author{
Gustavo Fernandez Ranvier, MD, PhD*, Benjamin Lieberman, DO, Aryan Meknat, MD and \\ Daniela E. Guevara, MD
}

Department of Surgery, Mount Sinai Hospital, Icahn School of Medicine at Mount Sinai, USA

\begin{abstract}
Background: The transoral endoscopic thyroidectomy vestibular approach (TOETVA) is a remote access endoscopic approach that results in the disruption of the mucosa in the oral cavity. Despite its growing popularity, consensus has not been reached regarding the optimal type and duration of perioperative antibiotics.
\end{abstract}

Methods: We conducted a literature review examining the use of perioperative antibiotics during TOETVA. We compared the infection rate in studies that used only prophylactic antibiotic regimens ( $<24$ hours), with extended antibiotic regimens (> 24 hours).

Results: A PubMed literature review yielded 268 reports after searching for TOETVA or Transoral Thyroidectomy. Twentyseven of those mentioned the antibiotic regimen of their series and were included in this analysis. In total, 1887 TOETVA cases were included. There was no significant difference in rate of infections between the two groups.

Conclusion: Based on our review, we do not see an increased risk of infection when only prophylactic antibiotics are used.

Keywords

TOETVA, Thyroidectomy, Antibiotics, Prophylaxis, Transoral thyroidectomy

\section{Introduction}

The traditional open cervical thyroidectomy is considered a clean procedure due to the absence of microbiologic contamination of the surgical field, especially as there is no disturbance of mucosa of the respiratory or gastrointestinal tracts [1]. These procedures have a very low rate of surgical site infection (SSI), estimated in the literature to be around $0.3 \%$ and $0.6 \%$ [2]. For this reason, antibiotic prophylaxis ( $p A B X)$ is not suggested for the trans-cervical approach to endocrine surgery by most national and international guidelines $[1,2]$. Despite this, many surgeons worldwide continue to routinely use $\mathrm{pABX}$. The debate as to whether the use of $\mathrm{pABX}$ is required is ongoing. While a large number of surgical societies recommend against antibiotic use in general (the caveat being that patients are not immunocompromised and/or are free of certain co-morbidities), its use is significantly influenced by social and geographic factors. For example, in England and Ireland 9\% of patients receive routine antibiotic prophylaxis, whereas in Italy and China $38.7 \%$ and $57.4-100 \%$ receive $\mathrm{pABX}$, respectively [2-5]. Without evidence-based oversight, the overuse of antibiotics in certain regions will invariably lead to negative repercussions such as an increase in antibiotic resistance and unnecessary costs [6].

The transoral endoscopic thyroidectomy vestibular approach (TOETVA) involves the removal of whole or part of the thyroid gland from three small incisions in the mucosa of the mouth. The transoral thyroidectomy was first approached through a sublingual route but later this technique was abandoned due to complications related to the violation of the floor of the mouth [7-9]. The transoral technique has evolved to using a vestibular approach and modifications of this technique gained popularity for the treatment of thyroid disease. This route entails the placement of three endoscopic ports in the vestibular area of the mouth with dissection carried out beneath the platysma muscle, first over the chin, then down between the two strap muscles [10-12].

*Corresponding author: Gustavo Fernandez Ranvier, MD, PhD, Division of Metabolic, Endocrine and Minimally Invasive Surgery, Department of Surgery, Mount Sinai Hospital, Icahn School of Medicine at Mount Sinai, USA, Tel: 212-241-5339

Accepted: June 18, 2021

Published online: June 21, 2021

Citation: Fernandez Ranvier G, Lieberman B, Meknat A, et al. (2021) Assessing the Role of Antibiotic Therapy in Transoral Endoscopic Thyroidectomy Vestibular Approach. J Surgical Endocrinol 3(1):89-93 
The mucosa of the oral cavity is colonized with a diverse bacterial flora. Because of the violation of the oral mucosa, these procedures are classified as clean contaminated cases (having controlled contamination of the operative field) assuming that there is no concomitant infectious process at the time of surgery (e.g. tooth abscess, etc.) $[1,13,14]$. In clean contaminated cases as well as in the transoral vestibular approach, unless otherwise indicated, only antibiotic prophylaxis is recommended.

A clarification between antibiotic prophylaxis and treatment is necessary in order to clearly understand the difference between the two. Antibiotic prophylaxis is when administration is within 1 hour of incision time and up to 24 hours after the operation, whereas antibiotic treatment is the administration after an infection has already begun [14]. Often, the administration of $\mathrm{pABX}$ requires a single dose within 60 minutes of incision time to provide adequate tissue concentration throughout the operation. Additional doses during the procedure are advisable if surgery is prolonged (i.e. greater than 4 hours), if there is major blood loss, or an antimicrobial with a short half-life is used [14]. The antibiotics should be discontinued no later than 24 hours after surgery, as the prolonged use of prophylaxis leads to bacterial resistance and increased hospital costs [14].

While the surgical technique of TOETVA has been refined throughout the years since its inception, the use of perioperative antibiotics is widely variable throughout institutions. The purpose of this study is to review the current state of antibiotic use during TOETVA in the available literature to see if there is a difference in the rate of infection compared with length of antibiotic uses. The hope is that this can contribute to appropriate antibiotic recommendations in the future.

\section{Methods}

A comprehensive literature review was carried out on PubMed, using the search terms "TOETVA" or "Transoral Thyroidectomy". Only articles written in English were included. A total of 268 results were reviewed. Inclusion criteria included greater than five cases in a series, and those studies which described IV or oral antibiotics duration and infection rate. Exclusion criteria included less than 5 cases in a study, cadaver or animal studies, studies without mention of antibiotics or infections. Full exclusion process can be seen in Table 1. Type of antibiotics used was recorded when available, as well as specific infectious complications and how they were managed. Results were examined to determine differences outcome's between patients receiving prophylactic antibiotics versus extended antibiotics. Prophylactic antibiotics were defined as $<24$ hours of antibiotics, whereas extended antibiotics (eABX) were defined as $>24$ hours of antibiotics. Statistical analysis was performed using SAS. $\mathrm{P}<0.05$ was considered statistically significant.

\section{Results}

Out of the 268 studies reviewed, 27 studies were included in the analysis [15-39]. One of the studies was a prospective randomized trial examining prophylactic vs extended antibiotic use in TOETVA [38]. One study compared four different groups of patients receiving different antibiotic regimens [37]. A total of 29 different groups were examined which translates to a total of 1887 TOETVA cases. Five hundred and four cases $(41 \%)$ received $\mathrm{pABX}$ only. One thousand three hundred and eighty-three cases received eABX (59\%). In the extended group, the average time of IV antibiotics was 2 days. The average length of oral antibiotics was 3.2 days.

A total of 15 infections were noted, 6 from the $\mathrm{PABX}$ group (1.1\%) and 9 from the extended antibiotic group (0.6\%). There was no statistically significant different between the rate of infections in the two groups (Table 2). Specified infections included chin cellulitis, pharyngitis, abscess and infected seroma. Two abscesses required surgical drainage in the operating room. One seroma was treated with needle aspiration and antibiotics. The management of the other infections was not specified.

The most common IV antibiotic regimens were amoxicillin/ clavulanic acid; cefazolin and metronidazole; and clindamycin. The most common oral antibiotic regimen, if specified, was amoxicillin/clavulanic acid. A more complete list of antibiotic regimens can be seen in Table 3 .

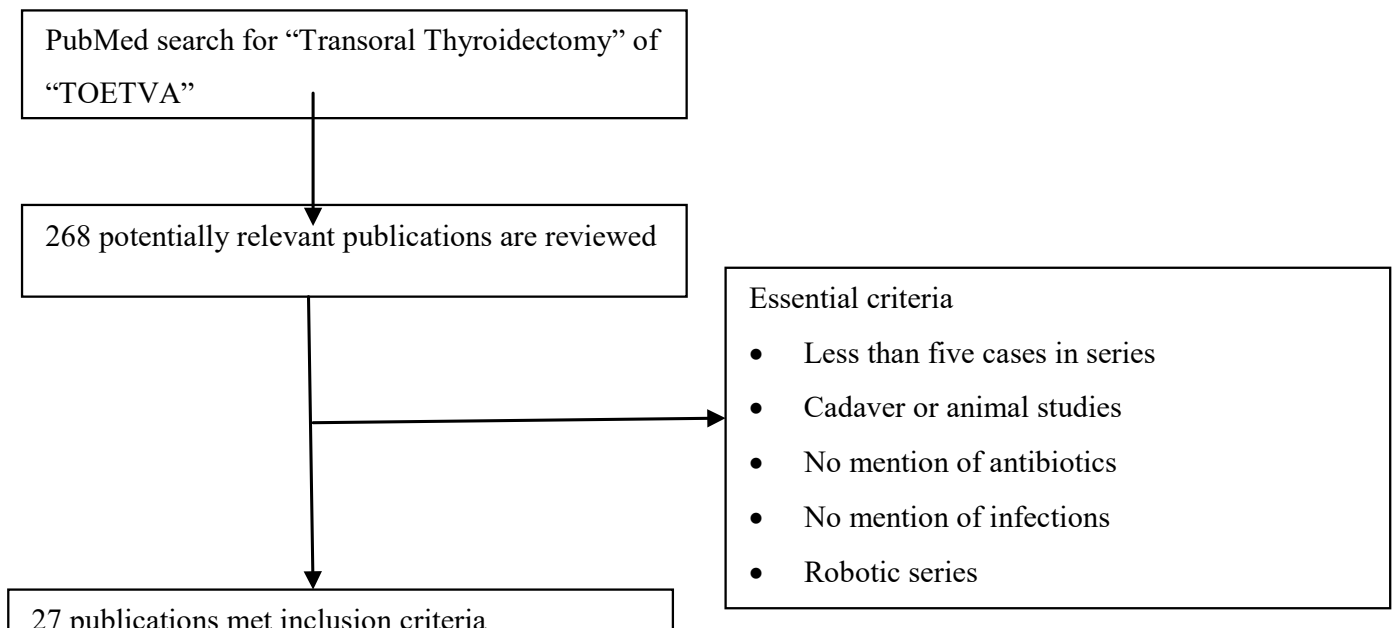

Table 1: Exclusion criteria. 
Citation: Fernandez Ranvier G, Lieberman B, Meknat A, et al. (2021) Assessing the Role of Antibiotic Therapy in Transoral Endoscopic Thyroidectomy Vestibular Approach. J Surgical Endocrinol 3(1):89-93

Table 2: Differences in Antibiotic Duration and Rates of Infection Between the Prophylactic Only and Extended Antibiotic Groups.

\begin{tabular}{|l|c|c|c|c|}
\hline & $\begin{array}{c}\text { Prophylactic Antibiotics } \\
\text { Only }\end{array}$ & Extended Antibiotics & Total & P-value \\
\hline Number of Studies & 11 & 16 & 27 \\
\hline $\begin{array}{l}\text { Number of Patients } \\
\text { Average IV antibiotic time } \\
\text { (days, standard deviation) }\end{array}$ & $504(26.7 \%)$ & $1383(73.3 \%)$ & 1887 \\
\hline $\begin{array}{l}\text { Average PO antibiotic time } \\
\text { (days, standard deviation) }\end{array}$ & 1 & $2(1.6)$ & 2 \\
\hline Number of Infections & $6(1.2 \%)$ & $5.1(2.6)$ & 3.1 & \\
\hline
\end{tabular}

IV: intravenous; PO: per os

Table 3: Most Commonly Listed IV and PO Antibiotics.

\begin{tabular}{|l|}
\hline Most Common IV Antibiotics \\
\hline Amoxicillin/Clavulanic Acid \\
\hline Ampicillin/Sulbactam \\
\hline Ancef and Metronidazole \\
\hline Cefazedone \\
\hline Cefotetan \\
\hline Clindamycin \\
\hline Oxacephem \\
\hline Most Common PO antibiotics \\
\hline Amoxicillin/Clavulanic Acid \\
\hline
\end{tabular}

There was one prospective trial comparing prophylactic antibiotics only to extended antibiotics in TOETVA [38]. Twenty-five patients in each group participated. Both groups received a second-generation cephalosporin pre-operatively. The extended antibiotic group received amoxicillin/clavulanic acid orally for 7 days post-operatively. There were no surgical site infections in either group.

\section{Discussion}

In the 12 years since its origin in 2008, TOETVA and its development have been of great interest to the endocrine surgery community, with many favorable reports of its use throughout the world. Well received by patients and surgeons alike, the technique has been refined and improved. One area that requires further development is the topic of perioperative antibiotics in TOETVA. Prolonged antibiotic use when not indicated will lead to an increase in antibiotic resistance and unnecessary costs [6]. While many surgeons have moved to only using prophylactic antibiotics (less than 24 hours), the original methodology described multiples days of IV and oral antibiotics [10]. In our review, we found that $73 \%$ of patients who underwent TOETVA were given extended duration of antibiotics. This is despite the fact that there was no increase in the rate of infections when the length of antibiotic therapy is decreased to prophylactic antibiotics only.

The difference in duration of antibiotic use is partially socio-cultural as well. Two series compared the length of stay of TOETVA patients in the US and Italy, and found to have no increased complications when sending patients home on day of surgery $[25,39]$. In Asia it can be more common to have patients stay in the hospital longer before transitioning to home care. Here we see longer IV and oral antibiotic use [17].
The oral flora is composed of 750 different types of bacteria, ranging from aerobic gram-positive cocci to gramnegative anaerobes [1]. Therefore, antibiotic choice for both prophylaxis and therapy should strive to cover a broad range of gram positive and negative aerobes and anaerobes. In our study, we saw that all institutions used broad spectrum antibiotics, most commonly second generation cephalosporins with or without metronidazole, amoxicillin/ clavulanic acid, or ampicillin/sulbactam. If oral antibiotics were used, only amoxicillin/clavulanic acid was listed.

In our literature review, only one prospective randomized trial was found to address antibiotic use in TOETVA [38]. Fifty patients were split into two equal groups. The control group which would receive IV antibiotics at the time or surgery as well as seven days of amoxicillin/clavulanic acid, and the experimental group which would receive only IV antibiotics at the time of surgery. Primary endpoint was signs of infection on the first post-operative day. They did not find a difference in the rate of infection between the two groups. They did find that patients in the antibiotic treatment group had an incidence of gastrointestinal upset not seen in the prophylactic only group, which they conclude is from the antibiotics.

One area of further study would be to examine the use of post-operative drains in TOETVA. The most cited technique for TOETVA calls for the use of post-operative drains, but some centers no longer use them, or no longer use them for all cases. Drain use is intended to decrease fluid collection which can become infected, but their impact on surgical site infection and antibiotic duration ("covering the drain") is not entirely clear [40]. Their use and effect on seroma formation or infection rate was not specifically examined in this study.

\section{Conclusion}

Based on current guidelines, no pABX are necessary for the traditional cervical approach to a thyroidectomy. Similar guidelines have not been set for TOETVA. Based on its cleancontaminated wound class, it would be reasonable to only use pABX for TOETVA. In our literature review we see up to $73 \%$ of patients undergoing TOETVA will receive an extended duration of antibiotics. Based on our review, we do not see an increased incidence of infection when only $\mathrm{pABX}$ are used. As the popularity of TOETVA continues to grow around the world, it is necessary to have a better understanding of what length of antibiotic therapy is necessary to help decrease the risk of antibiotic resistance and decrease costs. 


\section{Acknowledgements}

This project was supported in part by grant TL1TR0014341 from the National Center for Advancing Translational Sciences, National Institutes of Health.

\section{References}

1. Salmeron-Escobar J, De Velasco A (2006) Antibiotic prophylaxis in oral and maxillofacial surgery. Med Oral Patol Oral Cir Bucal 11: 292-296.

2. Avenia N, Sanguinetti A, Cirocchi R, et al. (2009) Antibiotic prophylaxis in thyroid surgery: A preliminary multicentric experience in Italy. Ann Surg Innov Res 3: 10.

3. American society of health-system pharmacists (1999) ASHP therapeutic guidelines on antimicrobial prophylaxis in surgery. Am J Health Syst Pharm 56: 1839-1888.

4. Jacob Moalem, Daniel Ruan, Rachel Farkas, et al. (2010) Patterns of antibiotic prophylaxis use for thyroidectomy and parathyroidectomy: results of an international survey of endocrine surgeons. J Am Coll Surg 210: 949-956.

5. Qiang Lu, Shu-Qin Xie, Si-Yuan Chen, et al. (2014) Experience of 1166 thyroidectomy without use of prophylactic antibiotics. Biomed Res Int.

6. Carl Llor, Lars Bjerrum (2014) Antimicrobial resistance: Risk associated with antibiotic overuse and initiative to reduce the problem. Ther Adv Drug Saf 5: 229-241.

7. Witzel K, von Rahden BHA, Kaminski C, et al. (2008) Transoral access for endoscopic thyroid resection. Surg Endosc 22: 18711875.

8. Benhidjeb T, Wilhelm T, Harlaar J, et al. (2009) Natural orifice surgery on thyroid gland: Totally transoral video-assisted thyroidectomy (TOVAT): Report of first experimental results of a new surgical method. Surg Endosc 23: 1119-1120.

9. McHenry CR (2011) Endoscopic minimally invasive thyroidectomy: A prospective proof-of-concept study in humans. World J Surg 35: 552.

10. Anuwong A (2016) Transoral endoscopic thyroidectomy vestibular approach: A series of the first 60 human cases. World J Surg 40: 491-497.

11. Richmond JD, Holsinger FC, Kandil E, et al. (2011) Transoral robotic-assisted thyroidectomy with central neck dissection: Preclinical cadaver feasibility study and proposed surgical technique. J Robot Surg 5: 279-282.

12. Anuwong A, Ketwong K, Jitpratoom P, et al. (2018) Safety and outcomes of the transoral endoscopic thyroidectomy vestibular approach. JAMA Surgery 153: 21-27.

13. Chai YJ, Chung JK, Anuwong A, et al. (2017) Transoral endoscopic thyroidectomy for papillary thyroid microcarcinoma: Initial experience of a single surgeon. Ann Surg Treat Res 93: 70-75.

14. Christopher Kamel, Monika Mierzwinski-Urban, John Embil (2011) Preoperative skin antiseptic preparations and application techniques for preventing surgical site infections: A systematic review of the clinical evidence and guidelines. Canadian Agency for Drugs and Technologies in Health, Ottowa.

15. Park JO, Park YJ, Kim MR, et al. (2019) Gasless transoral endoscopic thyroidectomy vestibular approach (gasless TOETVA). Surg Endosc 33: 3034-3039.
16. Park JO, Sun DI (2017) Transoral endoscopic thyroidectomy: our initial experience using a new endoscopic technique. Surg Endosc 31: 5436-5443.

17. Anuwong A, Sasanakietkul T, Jitpratoom P, et al. (2018) Transoral endoscopic thyroidectomy vestibular approach (TOETVA): Indications, techniques and results. Surg Endosc 32: 456-465.

18. Jitpratoom P, Ketwong K, Sasanakietkul T, et al. (2016) Transoral endoscopic thyroidectomy vestibular approach (TOETVA) for Graves' disease: A comparison of surgical results with open thyroidectomy. Gland Surg 5: 546-552.

19. Rege SA, Janesh M, Surpam S, et al. (2019) Transoral endoscopic thyroidectomy using vestibular approach: A single center experience. J Postgrad Med 65: 81-86.

20. Ahn JH, Yi JW (2020) Transoral endoscopic thyroidectomy for thyroid carcinoma: outcomes and surgical completeness in 150 single-surgeon cases. Surg Endosc 34: 861-867.

21. Yi JW, Yoon SG, Kim HS, et al. (2018) Transoral endoscopic surgery for papillary thyroid carcinoma: Initial experiences of a single surgeon in South Korea. Ann Surg Treat Res 95: 73-79.

22. Pérez-Soto RH, Ponce de León-Ballesteros G, MontalvoHernández J, et al. (2019) Transoral endoscopic thyroidectomy by vestibular approach-initial experience and comparative analysis in the first reported Mexican cohort. J Laparoendosc Adv Surg Tech A 29: 1526-1531.

23. Nguyen HX, Nguyen LT, Nguyen HV, et al. (2020) Comparison of transoral thyroidectomy vestibular approach and unilateral axillobreast approach for endoscopic thyroidectomy: A prospective cohort study. J Laparoendosc Adv Surg Tech A 31: 11-17.

24. Dionigi G, Bacuzzi A, Lavazza M, et al. (2017) Transoral endoscopic thyroidectomy: Preliminary experience in Italy. Updates Surg 69: 225-234.

25. Nguyen HX, Nguyen HX, Nguyen HV, et al. (2020) Transoral endoscopic thyroidectomy by vestibular approach with central lymph node dissection for thyroid microcarcinoma. J Laparoendosc Adv Surg Tech A 31: 410-415.

26. Lira RB, Ramos AT, Nogueira RMR, et al. (2020) Transoral thyroidectomy (TOETVA): Complications, surgical time and learning curve. Oral Oncol 110: 104871.

27. Lou Y, Chen R, Fu N, et al. (2020) Transoral endoscopic thyroidectomy vestibular approach (TOETVA) in the perioperative mode of day ward. Am Surg.

28. Kim SY, Kim SM, Makay Ö, et al. (2020) Transoral endoscopic thyroidectomy using the vestibular approach with an endoscopic retractor in thyroid cancer: Experience with the first 132 patients. Surg Endosc 34: 5414-5420.

29. Le QV, Ngo DQ, Tran TD, et al. (2020) Transoral endoscopic thyroidectomy vestibular approach: An initial experience in Vietnam. Surg Laparosc Endosc Percutan Tech 30: 209-213.

30. Tesseroli MAS, Spagnol M, Sanabria Á (2018) Transoral endoscopic thyroidectomy by vestibular approach (TOETVA): Initial experience in Brazil. Rev Col Bras Cir 45: e1951.

31. Fernandez-Ranvier G, Meknat A, Guevara D, et al. (2020) Transoral endoscopic thyroidectomy vestibular approach: A single-institution experience of the first 50 cases. Surg Innov 27: 439-444. 
32. Xu Z, Song J, Wang Y, et al. (2019) A comparison of transoral vestibular and bilateral areolar endoscopic thyroidectomy approaches for unilateral papillary thyroid microcarcinomas. Wideochir Inne Tech Maloinwazyjne 14: 501-508.

33. Sun $H$, Zheng $H$, Wang $X$, et al. (2020) Comparison of transoral endoscopic thyroidectomy vestibular approach, total endoscopic thyroidectomy via areola approach, and conventional open thyroidectomy: A retrospective analysis of safety, trauma, and feasibility of central neck dissection in the treatment of papillary thyroid carcinoma. Surg Endosc 34: 268274.

34. Fu J, Luo $Y$, Chen $Q$, et al. (2018) Transoral endoscopic thyroidectomy: Review of 81 cases in a single institute. J Laparoendosc Adv Surg Tech A 28: 286-291.

35. Bakkar S, Al Hyari M, Naghawi M, et al. (2018) Transoral thyroidectomy: A viable surgical option with unprecedented complications-a case series. J Endocrinol Invest 41: 809-813.
36. Udelsman R, Anuwong A, Oprea AD, et al. (2016) Trans-oral vestibular endocrine surgery: A new technique in the United States. Ann Surg 264: e13-e16.

37. Fernandez Ranvier G, Meknat A, Guevara DE, et al. (2020) International multi-institutional experience with the transoral endoscopic thyroidectomy vestibular approach. J Laparoendosc Adv Surg Tech A 30: 278-283.

38. Yi JW, Kim SJ, Lee KE (2020) Evaluation of the efficacy of postoperative antibiotic treatment in transoral endoscopic thyroidectomy: A prospective randomised controlled trial. $\mathrm{Br} \mathrm{J}$ Oral Maxillofac Surg 58: 334-340.

39. Fernández-Ranvier GG, Guevara D, Alawwa G, et al. (2020) Feasibility of the TOETVA as an ambulatory procedure. J Surgical Endocrinol 2: 49-54.

40. Reiffel AJ, Barie PS, Spector JA (2013) A multi-disciplinary review of the potential association between closed-suction drains and surgical site infection. Surg Infect (Larchmt) 14: 244-269. 